\title{
Development of the service of obstetrics and childhood in the Chechen republic
}

Keywords: obstetrics, chechen republic, infant mortality, ultrasound screening, biochemical screening, DACC, NSA, HT1

\section{Introduction}

The Chechen Republic is a constituent entity of the Russian Federation and is part of the North Caucasian Federal District. It borders on the west with the Republic of Ingushetia, in the northwest with the Republic of North Ossetia-Alania, in the north - with the Stavropol Territory, in the north-east and east - with the Republic of Dagestan, in the south - with Georgia. The area of the Chechen Republic is 16.3 thousand $\mathrm{km}^{2}$, the population density is almost 86 people per $\mathrm{km}^{2}$. The region belongs to the territories with a high population density. On the territory of the Chechen Republic there are 5cities: the capital - Grozny, Argun, Gudermes, Urus-Martan, Shali, as well as 15 municipal districts. Official languages: Chechen and Russian.

In the period of the socio-political crisis in Russia, when from 1994 to 2000, due to certain reasons, the republic turned into a zone of economic disaster, $80 \%$ of the republic's infrastructure was destroyed, more than $70 \%$ of medical specialists left the republic, which led to an acute shortage of staff. Practical recovery of the health care system is an industry began in 2000 and subsequent years. 20years of a difficult stage of restoration and formation of the republican public health services have passed before it was possible to rebuild new institutions, to restore houses, to relatively fill the quantitative composition of medical workers,

The population of the Chechen Republic as of January 1, 2017 is (according to official data) 1414865 people, including: the urban population is 492939 people (34.8\%), the rural population - 921926 people $(65.2 \%)$. The child population of the republic is 530432 people (37.5\% of the total population).

Russian President Vladimir Putin in his message to the Federal Assembly stressed that the meaning of the state's policy is the saving of people, the multiplication of human capital, both the main wealth of Russia as a whole, and each individual in particular. Today, even in a difficult social and economic situation, the healthcare system of the Chechen Republic manages to achieve positive changes in the health indicators of the population. Undoubtedly, it is the merit of the correctly planned strategy of the Ministry of Health of Russia headed by Veronika Igorevna Skvortsova, the taken course for improving the well-being of the republic's population of the Head of the Chechen Republic, Ramzan Akhmatovich Kadyrov.

In recent years, the republic is gaining momentum in reducing many socially significant indicators in the direction of improvement. All this became possible due to a reduction in mortality from all the main causes, but a more significant contribution to an increase in life expectancy was the reduction in infant mortality. The state of health of the younger generation is an important indicator of the well-being of society and the state, reflecting not only the present situation, but also the forecast for the future. As is known, the Chechen Republic for a long time occupied "advanced" positions on indicators of infant
Volume 3 Issue 2 - 2017

\author{
Irbayeva Taisiya \\ Head of the department of childhood and chief pediatrician, \\ Ministry of Health of the Chechen Republic, Russia
}

Correspondence: Irbayeva Taisiya, Head of the department of childhood and chief pediatrician, Ministry of Health of the Chechen Republic, Russia, Email irbaieva_mz@mail.ru

Received: November 27, 2017| Published: November 28, 2017

mortality. It is worth recalling that in 2012 the Ministry of Health of Russia introduced the international criteria for live birth, and in accordance with this it was forecasted an increase of $30 \%$, but nevertheless, thanks to the organizational and practical measures taken, it was possible to reduce the indicator. In 2016, the infant mortality rate was 10.2 per 1,000 live births, which is $55.4 \%$ lower than in 2012, when the indicator was 22.9per 1,000 live births. For the period January-July 2017, the infant mortality rate was 8.4 per 1,000 births. In general, infant mortality declined by $55 \%$ over the past 5years and amounted to 0.9 per 1,000 children.

An important role in reducing the infant mortality rate was played by the implementation of federal and regional programs aimed at developing the health of the Chechen Republic. With the purpose of revealing and early setting up of pregnant women, the underworld rounds of midwives are organized and introduced. Thanks to the work carried out, the number of pregnant women diagnosed during the household trips every year to 12 weeks in rural areas increases. To improve the quality and accessibility of medical care for women during pregnancy and the postpartum period, mobile mobile teams have been set up for trips to remote areas of the republic, including: obstetrician-gynecologist, therapist, doctor of ultrasound, dentist, laboratory assistant, midwife. To date, there are 34 exit brigades. In addition, the indicators for prenatal prenatal diagnosis have improved. Over the past 5years, the proportion of coverage of pregnant women increased by three-time ultrasound screening to $93 \%$, and biochemical screening to $60 \%$.

A more qualitative approach to pregnant women at the primary level, compliance with the routing of pregnant women taking into account risk groups, did not slow to give a result that was reflected by an increase in the proportion of normal births at level 1, a decrease in the proportion of premature births at level 1 , which in turn enabled focus on "pathological" births at levels 2 and 3. In order to reduce child, including infant mortality, through detailed analysis, a forecast "roadmap" for each medical institution was developed. Much attention is paid to the educational work among adolescent girls and women of reproductive age on women's health problems and the need for timely treatment in women's clinics. On this issue, television 
programs have been organized, mother's schools have been set up at women's consultations, and rooms for medical and psychological assistance have been set up. A new structural subdivision, the Remote Obstetric Consultative Center (DACC), was also established with an outpatient obstetrical and resuscitation team on the basis of the GBU "Resp. Also, a new structural unit was set up - the Remote Midwifery Consultative Center (DACC) with an on-site obstetric and resuscitation team on the basis of the State Health Center of the Republican Center for the Protection of Maternal and Child Health. A.N. Kadyrova, whose main goal is to provide highly qualified counseling, medical and diagnostic and preventive care to pregnant women, parturients and puerperal from the group of increased perinatal risk of obstetrical complications. And on the basis of the State Institution "Republican Children's Clinical Hospital. E.P. Glinka "organized an outreach consultative and resuscitation neonatal brigade for the provision of resuscitative and emergency care for newborns.

All ongoing work, from women's consultations to maternity wards, is conducted with the aim of delivering a premature baby in a natural incubator to an institution where medical care for a pregnant and newborn child is provided at the proper level. In order to provide timely and quality care for women during pregnancy, childbirth and the puerperium, and to prevent the refusal of observation, examination and timely hospitalization of pregnant high and medium risk groups, the Ministry of Health of the Chechen Republic issued an order in 2015 that obliges the head of the medical institution, with the refusal of examination and hospitalization of the pregnant woman, to connect local authorities to the solution of this problem, including g lava administrations, clergy and police. Due to this step, the problem of narrowly medical became public, which was accepted positively by the population. With the support of the relevant department of the Russian Ministry of Health, over 200 obstetrician-gynecologists, anaesthesiologists-resuscitators, neonatologists, nurses of obstetrical institutions in the workplace in the republic under the guidance of the faculty of the central medical bases of the Russian Federation, including : "Scientific Center of Obstetrics, Gynecology and Perinatology. IN AND. Kulakov, Yaroslavl State Medical University, St. Petersburg State Pediatric University, North-West State Medical University named after II Mechnikov, Saint Petersburg Research Institute of Obstetrics and Gynecology named after DO Otta, Federal Center of the Heart, Blood and Endocrinology im. V.A. Almazov », « Rostov Research Institute of Obstetrics and Pediatrics ».

Since 2015, jointly with the Ministry of Health of Russia, a Plan of Measures to Reduce Infant Mortality has been developed. It is annually updated and coordinated with the Department of Medical Care for Children and the Ministry of Health of the Russian Federation Ministry of Health and the chief freelance neonatologist of the Ministry of Health of Russia. Ivanov. As part of the implementation of the Plan, measures are taken to prevent non-congestion. The planned index of preterm delivery in the country is $5.6 \%$. At the end of 2016 , the share of preterm birth was $4.7 \%$ (in the Russian Federation 5.8\%). Clinical recommendations (protocols of treatment) "Premature birth" and "Miscarriage in early pregnancy: diagnosis and tactics of reference" have been put into practice. The Order and the List of routing for miscarriages and premature births have been developed.

In October 2016, a new institution of the Maternity Hospital was opened on Dudayev Boulevard, which is planned to be upgraded in 2017 with the necessary modern equipment, with the deployment of structural offices to make it a Perinatal Center. This institution will be specialized in providing medical care to pregnant women, puerperas with premature birth, as well as newborns with low and extremely low body weight.

In the Chechen Republic, since 2011, together with the Foundation for Social and Cultural Initiatives (FSI), whose president is Svetlana Medvedeva, every year an action "Give me life!" is held. The action is closely connected with the Day of Family, Love and Fidelity and is held during the week from 9 to 15 July. In 2016, the campaign covered up to 35 thousand women's population.

On the initiative of the Federal State Educational Institution "National Scientific and Practical Center for Children's Health" of the Russian Ministry of Health in 2016, the Chechen Republic was chosen as one of the territories for the implementation of the pilot project "Development of the School Medicine Network in Eastern Europe and Central Asia" and the audit of the pediatric service. Within the framework of these projects, a team of specialists of the NCPC together with specialists from the State Institution " E.P. Glinka periodically conduct screening examinations of schoolchildren aged 11 and $15 y$ years and audit the quality of medical care provided to the children of the republic.

In the future, in the framework of the project "Development of the School Medicine Network in Eastern Europe and Central Asia", in the Chechen Republic it is planned to conduct additional consultations and examinations of those children who have been diagnosed with violations, carry out a re-diagnosis of all schoolchildren examined after 1.5-2 year, as well as the organization of training in emergency care for school staff and polyclinics. In autumn 2017, the results of the audit of the pediatric service are planned.

Also in 2016, a pilot project jointly with the Russian Society of Medical Genetics to improve the detection of hereditary metabolic diseases (NSA), including hereditary type 1 tyrosinemia (HT1) in the children's population of the Chechen Republic, was launched in the republic. In the healthcare sector of the Chechen Republic, the current problem of the shortage of medical personnel is the main and the most priority and requires the adoption not only of complex measures by various departments, but the creation of a targeted state mechanism to provide the industry with qualified personnel. The leadership of the Ministry of Health of the Chechen Republic especially accentuates attention to this industry issue.

For a gradual transition to the approval of the Concept of the Personnel Policy in the Health Care of the Chechen Republic, a comprehensive plan was developed to train highly qualified medical personnel and phased exit, from the situation created, approved by the Chechen Republic's leadership, and including:

1. Analysis of the personnel service of the structural divisions of the healthcare sector of the Chechen Republic, to determine the most sought-after specialties in a particular medical organization, taking into account the number of people living, the profile and the skill level of specialists.

2. The direction of citizens of the Chechen Republic in the federal medical educational institutions of the subjects of the Russian Federation and the Chechen Republic for obtaining higher medical education. Conclusion of the agreement in conjunction with the district municipalities, mandatory return of graduates of medical universities to the Ministry of Health of the Chechen Republic for referral to work or continuing vocational education. 
3. Continuing professional education with the passage of a certification cycle in the specialty or accreditation of a specialist every 5years, the acquisition of related specialties in the program of additional vocational education, passage of thematic improvements in the specialty and other training courses for 2017 identified 590 specialist doctors.

4. The mandatory control, educational level of the doctor and nursing staff, taking into account the new criteria of the Ministry of Health of the Russian Federation, to specialists - availability of qualification categories, regularly confirmed by the commission of the Ministry of Health of the Chechen Republic.

At this time, the draft Concept of personnel policy is being updated in connection with the adoption of the priority direction of the Ministry of Health of the Russian Federation to scale up the accreditation of primary care specialists and to provide actual financial support for measures of social support to medical personnel in rural areas.

As a result of the implementation of the planned activities, it is planned to eliminate the shortage of specialists of medical and paramedical personnel by 2018 and by 2019 to come out with a small managed surplus of 3.5-4.5, keeping it at the specified level constantly. The Ministry of Health of the Chechen Republic is carrying out certain work on an efficiently functioning system of moral and material incentives that contributes to the prestige of the medical professions. In 2017, a solemn event was held dedicated to the celebration of the "Day of Medical Worker", with the participation of the Head of Chechen, where the best and most responsible employees of all professional groups were awarded and honored for their services in the healthcare sector:

a. The title "Honored Doctor of the Chechen Republic" was given to 9employees;

b. The title of "Excellent Public Health of the Russian Federation" was given to $12 \mathrm{employees;}$

c. The title of "Excellent worker in the health of the Chechen Republic" was given to 8employees.

Many distinguished workers were awarded letters and letters of thanks of the Head of the Chechen Republic, the Government of the Chechen Republic, the Ministry of Health of the Russian Federation, the Parliament of the Chechen Republic and the Ministry of Health of the Chechen Republic. Also in many medical organizations were held contests "Best Nurse", "Best Midwife" and on the basis of local competitions on the basis of the RCCH. E.P. Glinka conducted an event dedicated to the International Day of the Nurse.

\section{Acknowledgements}

None.

\section{Conflict of interest}

Author declares that there is no conflict of interest. 